\title{
Investigating the PDR process in a UK university: continuing professional development or performativity?
}

Article

Accepted Version

Floyd, A. ORCID: https://orcid.org/0000-0002-2008-7831 (2019) Investigating the PDR process in a UK university: continuing professional development or performativity? Professional Development in Education (formerly Journal of Inservice Education), 48 (2). pp. 315-329. ISSN 1941-5257 doi: https://doi.org/10.1080/19415257.2019.1696874 Available at https://centaur.reading.ac.uk/87175/

It is advisable to refer to the publisher's version if you intend to cite from the work. See Guidance on citing.

To link to this article DOI: http://dx.doi.org/10.1080/19415257.2019.1696874

Publisher: Taylor and Francis

All outputs in CentAUR are protected by Intellectual Property Rights law, including copyright law. Copyright and IPR is retained by the creators or other copyright holders. Terms and conditions for use of this material are defined in the End User Agreement. 


\section{CentAUR}

Central Archive at the University of Reading

Reading's research outputs online 
Investigating the PDR process in a UK university: continuing professional development or performativity?

\author{
Alan Floyd* \\ Institute of Education, University of Reading, Reading, UK \\ *alan.floyd@ reading.ac.uk
}




\title{
Investigating the PDR process in a UK university: continuing professional development or performativity?
}

\author{
Over recent years, the professional development review process has risen in \\ importance in universities with such exercises being shown to have a positive \\ effect on student learning, staff motivation, recruitment and retention. However, \\ they may also be perceived as a controlling mechanism and part of a culture of \\ 'performativity', which implies a lack of trust, an undermining of autonomy and \\ a reliance on externally driven targets to 'manage' staff. However, there is very \\ little published research in this area. This paper addresses this knowledge gap by \\ drawing on data from a Leadership Foundation funded study in a UK University \\ which included 30 interviews and a follow up survey $(n=177)$ with both leaders \\ and the staff they lead. The findings suggest that both leaders and staff felt that \\ the process was potentially very important and could offer significant levels of \\ guidance and support for professional development. However, they stressed the \\ importance of a review structure which was adaptable, more professionally \\ relevant, and less reliant on over ambitious target setting.
}

Keywords: academic leaders; professional development review; higher education; academic staff; performativity

\section{Introduction}

Over recent years, factors affecting higher education such as globalisation, changing funding models, increased competition, and a rapidly changing student body have meant that an academic's role has become increasingly complex (Makunye and Pelser 2012). Consequently, institutional professional development review (PDR) processes have risen in importance, as well-planned and individualised continuing professional development (CPD) programmes for academic staff have been identified as a crucial aspect of supporting them through these challenging times (Floyd 2016; Gerken et al. 2016; Preston and Floyd 2016).

Although historically professional development initiatives have not been prioritised in the sector due to a focus on research, global market changes and the 
growth of online and private providers has meant that such activities are now becoming more significant across the World (Mulà et al. 2017). This shift reflects the fact that senior university managers are now seeing the value of introducing professional development programs for the staff working in their organisations. Such professional development planning and support has also been identified as being vital for the growing number of sessional staff working in non-permanent positions in the higher education sector (Hitch et al. 2018).

It has been shown that CPD programmes and their associated review and strategic planning processes can have positive effects on staff motivation, recruitment and retention and are an essential part of modern organizational practice, potentially having a major positive impact on teaching and learning processes and student outcomes (De Rijdt et al. 2013; Saroyan and Trigwell 2015; Williams et al. 2016). However, the proliferation of New Public Management practices across the sector (Deem et al. 2007), combined with universities being viewed as corporate enterprises in response to increased pressures of accountability-related measures such as research assessment exercises, teaching excellence frameworks, quality assurance procedures and national and international ranking tables (Bremner 2011) has had a significant impact on such activities. These changes have meant that the annual review process (PDR or equivalent) which is purported to review the professional development needs of staff and set out future development plans may also be perceived as a controlling mechanism and part of a culture of 'performativity', which implies a lack of trust and a reliance on externally driven tasks and targets to 'manage' staff (Ball 2012). Perceived this way, the review process may actually have a negative impact on staff morale and behaviour, which can undermine organisational effectiveness and lead to decreased performance, staff absence and increased turnover (Teh et al. 2012). Such a 
performative culture can also be seen as a threat to traditional academic values such as autonomy and credibility (Lambrechts et al. 2017).

Although there is a growing body of research looking at professional development in higher education (Gast et al. 2017), to date there is very little empirical evidence as to how the PDR process (or equivalent) is experienced by both leaders and the staff they lead, a fact which is surprising given its increasing use and perceived importance in the sector. Indeed it has been argued that perspectives of 'the led' have been overlooked and ignored by almost all previous higher education leadership research (Evans et al. 2013). The purpose of this paper, therefore, is to fill this gap by reporting on a Leadership Foundation funded study which, in part, explored academics' and managers' perceptions of the process at a case study institution. By comparing data from both managers and academics to explore how the process is both espoused and enacted (Argyris et al. 1985; Argyris and Schon 1974) in one case study institution, and using an analytical framework based on the concepts of professional development and performativity, the article provides a significant and original contribution to our knowledge in this area.

\section{Conceptual Framework}

In this study, two key concepts are juxtaposed, namely continuing professional development and performativity, to help provide new theoretical insights into the PDR process in today's higher education climate. This analytical framework has been used elsewhere, such as in a previous study exploring higher education lecturers' response to feedback (Arthur 2009), but has not, so far as the author is aware, been used to better understand academic reviewers' and reviewees' experiences of the PDR process in the UK. In this study, CPD is defined as 'all formal and informal learning that enables 
individuals to improve their own practice' (Bubb and Earley 2007, p. 3) which is linked to the notion that one of the key characteristics of being a professional is continuingly learning throughout one's career. In contrast, based on neo-liberal principles and linked to the New Public Management agenda, performativity has been conceptualised by Ball (2003) to include aspects of regulation and productivity measurement which can negatively impact on professional identity and bring in to question the very nature of what it means to be an academic (Ball 2012). The argument here is that the autonomy and trust of the profession is under threat as a consequence of over relying on business related practices such as setting externally driven performance goals (using terms such as key performance indicators) and linking these to rewards and sanctions to help improve productivity and performance; these practices are becoming increasingly important as part of the PDR process for those in academic job roles. In turn, these issues are exacerbated by the marketization of the sector which has led to growing internal and external quality assurance and accountability procedures, institutional and national student surveys, research assessment exercises, teaching excellence frameworks, and national and international published league tables (Floyd 2016).

Key questions that arise here include what is the purpose of the PDR process in increasingly corporate organisational environments within higher education? For example, is it seen as key professional developmental process or as a means of monitoring and control? And how are these purposes perceived and experienced on the ground? These questions link to ideas of espoused theory versus theory-in-use (Argyris et al. 1985; Argyris and Schon 1974): these authors argue that there are two kinds of theories that can explain human action. They explain by drawing on an example from their research: 
Espoused theories are those that an individual claims to follow. Theories-in-use are those that can be inferred from action. For example, when asked how he would deal with a disagreement with a client a management consultant said that he would first state what he understood to be the substance of the disagreement, and then discuss with the client what kind of data would resolve it. This was his espoused theory. But when we examined a tape recording of what the consultant actually did in that situation, we found that he advocated his own view and dismissed that of the client (Argyris et al. 1985, p. 81).

Such conflicting thinking and actions, which are often tacit, can help us understand how universities (and their leaders) view academic staff in the current context. For example, previous research analysing a corpus of policies, rules, and procedures being used in a number of institutions of higher education in Asia, focusing on the issues of transparency, power and control in academic appraisals and promotions, has shown that there are often inconsistencies in paperwork and that the espoused aims of the process as written in institutional policy documents - for instance citing staff development as a key aim - are not reflected in the more managerial 'theory in use' terms and used in the associated forms during the process - such as use of the term performance management (Bremner 2011). While it is acknowledged that this research was undertaken in a different cultural context, further questions arise from this work that are important to consider from the UK perspective: how can the PDR process and its associated paperwork best be delivered? And how do we ensure that the process is viewed as a positive aspect of a well-planned continuing professional development programme and not seen as a controlling aspect of performativity?

The above discussion has outlined key concepts and theories related to the PDR process and identified some important emerging questions. In turn, these lead to the following research questions that this article will address:

- How is the PDR process espoused at a UK university? 
- To what extent do academics' and their leaders' perceptions of its enactment converge or differ?

- How can the PDR process best be developed in the future?

\section{Methods}

\section{Design}

Based on detailed methods previously described (Floyd and Fung 2017), the study adopted a two staged, qualitatively driven mixed methods approach (Morse and Niehaus 2009). An exploratory, sequential mixed methods design (Creswell 2014) was used, where qualitative data are gathered and analysed first before quantitative data are collected from a larger sample size. First, to identify emerging key themes and issues, interviews were conducted with 15 Academic Leaders (ALs) and 15 Academics (As) these were academics who were assigned to an AL for the purposes of their Professional Development Review. Second, we undertook a survey of all academic staff $(n=1034)$ using an online questionnaire (Bristol On-Line Surveys) which was based on the key themes and issues that emerged from the interviews and consisted of both closed and open-ended questions.

All data were collected at a Case Study University in England which is a research led institution and had recently introduced a new distributed leadership model and PDR process. In the new distributed leadership model, new middle leader roles called Academic Leads (ALs) were created with each responsible for a small group of academic staff (approximately 8 in each group). ALs were meant to work closely with Directors of Education and Directors of Research to provide leadership, guidance, support and advice to these staff as well as undertaking their professional development reviews. Further detail and impact of this model is explored elsewhere (see Floyd and 
Fung 2017; Floyd and Fung 2018). The new PDR process involved a range of annual meetings and associated paperwork, as well as a new 'portfolio' folder which was meant to help academics reflect on their professional development needs and goals. The process was purported to help translate institution wide strategies into individual objectives, while at the same time allowing for and supporting academics' personal goals and ambitions. In other words, the process was meant to align and reconcile individual staff development needs with the overall strategic direction and goals of the University.

\section{Participants}

Interview participants were identified using a list supplied by Human Resources at the Case Study University and invited to take part via email. To characterise as wide a range of experiences as possible, the interview sample contained male $(\mathrm{ALs}=9 ; \mathrm{As}=8)$ and female $(\mathrm{ALs}=6 ; \mathrm{As}=7)$ staff representing a variety of ages, levels of experience and discipline backgrounds. Table 1 shows the details of each interview group. To preserve anonymity, each participant has been given a pseudonym and only broad academic domain areas have been used to describe their academic discipline.

Table 1: Interview participants

\begin{tabular}{ccc|ccc}
\hline & Academic Leads & \multicolumn{3}{c}{ Academics } \\
\hline Name & Age & Domain & Name & Age & Domain \\
\hline Arthur & 33 & Natural Sciences & Amy & 32 & Social Sciences \\
Brandon & 60 & Natural Sciences & Bert & 35 & Natural Sciences \\
Chris & 55 & Social Sciences & Clare & 57 & Humanities \\
Diane & 49 & Social Sciences & Harold & 39 & Natural Sciences \\
Evelyn & 53 & Social Sciences & James & 35 & Social Sciences \\
Francis & 60 & Humanities & Jane & 45 & Social sciences \\
George & 35 & Social Sciences & John & 37 & Social Sciences \\
Howard & 44 & Humanities & Katherine & 52 & Natural Sciences \\
Ian & 49 & Natural Sciences & Matthew & 31 & Humanities \\
Jack & 39 & Humanities & Nick & 41 & Social sciences \\
Kendra & 50 & Humanities & Ruth & 28 & Natural Sciences \\
Lisa & 54 & Social Sciences & Sophie & 39 & Natural Sciences \\
Martin & 65 & Social Sciences & Sylvia & 44 & Social Sciences \\
Nel & 47 & Humanities & Tobias & 35 & Humanities \\
Oliver & 64 & Social Sciences & Terry & 54 & Social Sciences \\
\hline
\end{tabular}


Following the interviews, an invitation and link to the survey and was sent out via email to all academic staff at the institution with one reminder email sent two weeks later. The survey was completed by 177 academics ( $17.1 \%$ response rate). Of these, 42 were academic leads (32\% of all ALs, 17 female and 25 male) and 135 were academics (12\% of academic staff at the University, 69 female and 66 male).

\section{Research Instruments}

In the interviews, participants were asked to describe their experiences and perceptions of the review process using a semi-structured schedule based on themes that emerged from a review of extant literature. The schedule was peer reviewed and piloted before use. Final questions were based around key issues such as perceptions of the overall process, purpose of PDRs, experiences of training, perceived opportunities and challenges, training and development opportunities, links with career development, and reflections on reconciling individual and institutional goals.

Once the interview data had been analysed, the subsequent questionnaire was developed using the themes that emerged and in line with guidelines to help increase the validity in survey design (Gehlbach and Brinkworth 2011). A draft survey was subject to an initial peer review, followed by a validation piloting exercise. This involved sending the link to 10 academics and asking them to complete the survey and provide feedback on item clarity, appropriateness, and coverage of issues important to the PDR process. Several changes to wording were made following this exercise. The final survey contained 18 Likert scales questions where participants were asked whether they agreed with certain statements or not specifically related to the PDR process. For example, I am clear about the purpose of the PDR process with each answer based on a five-point agreement scale ranging from strongly agree to strongly disagree. Each 
section of the questionnaire also had an open comments section for participants to add qualitative comments about their responses if appropriate. Data were also collected regarding each participant's role, gender, age and length of time at the University alongside questions regarding the new distributed leadership model described earlier.

\section{Ethics}

The research followed ethical guidelines for educational research highlighted by the British Educational Research Association (2011). Following ethical approval, interview participants were sent an email invitation which included a detailed participant information sheet. Each participant was then asked to sign a consent form and interviewed for approximately one hour in their place of work; interviews were recorded and transcribed.

The survey link was emailed to all academic staff using a central mailing list supplied by Human Resources. The online questionnaire had a front sheet which identified the researchers and funder, the aims of the project, the ethical review process which had been followed, and a consent statement that said, "By completing this survey, you indicate your consent for your responses to be used for the purposes of research".

\section{Analysis}

The interview data were analysed following thematic analysis techniques outlined by Lichtman (2013) and suggestions for ensuring rigour in qualitative analysis described by Creswell (2014): each researcher coded each transcript separately and then grouped these codes together to form initial themes. The researchers then discussed and refined these emerging themes and related them to the study's conceptual framework, this allowed for inter-researcher agreement. Key overarching themes included overall 
purpose; underlying principles, paperwork and process; career planning; trust and honesty; effectiveness; training.

The results of the survey were analysed using descriptive statistics and crosstabulated to compare data from those who were academic leads with those who were academics. Chi-square tests were then carried out to see if there was an association between job role (academics and academic leads) and certain key measures ( $\mathrm{p}<0.05)$. This non-parametric test allowed us to explore whether our distribution of frequencies were significantly different from those expected by chance alone (Nardi 2018). Both sets of results were then combined and further analysed and are presented thematically below.

\section{Results}

\section{How do Academics perceive and experience the PDR process?}

\section{Overall purpose}

When discussing the aim of the PDR process, the interview data suggest that some academics had a sense that the real purpose was unclear. This uncertainty was summed up neatly by Nick:

I would like to know how [the PDR] was conceived; whether it was conceived for the sake of the individual development as is said, or was just conceived and created to try and get the most out of the individual staff for the bigger aim of the University?

In relation to this point, Terry spoke at some length arguing that there should be an investigation into the PDR process to examine different understandings of the nature of the process and to establish whether the PDR is focused on 'appraisal, compliance, control, improvement', or whether the process is 'just to alleviate people's stress'. He 
continued:

Is it a developmental review; is it a critical review? ... [We need] a better understanding of that, and ... a glossary of the vocabulary around it, so that we all understand what we mean when we say PDR, because I don't think people understand, you know?

Tobias viewed the perceived institutional lack of clarity as deliberate, so that university leaders can move the goalposts of success when necessary:

What the PDR values is ... very unclear, and I feel like it ... is purposefully unclear. It comes back to this feeling like we feel you've published the right amount; we feel this is enough to move into senior lectureship.

These uncertainties were also evident in the survey data. Although the majority of academics $(66 \%)$ were clear about the purpose of the PDR process, there were $26(19 \%)$ who were not, as can be seen in table 2 .

Table 2: Various Survey Responses

\begin{tabular}{|c|c|c|c|c|c|c|}
\hline \multirow[t]{2}{*}{ Answer Options } & \multicolumn{2}{|c|}{ Academics } & \multicolumn{2}{|c|}{$\begin{array}{l}\text { Academic } \\
\text { Leads }\end{array}$} & \multicolumn{2}{|c|}{ Total } \\
\hline & $\mathrm{n}$ & $\%$ & $\mathrm{n}$ & $\%$ & $\mathrm{n}$ & $\%$ \\
\hline \multicolumn{7}{|c|}{ I am clear about the purpose of the PDR process } \\
\hline Strongly Agree/Agree & 89 & 66 & 30 & 71 & 119 & 67 \\
\hline Neither Agree nor Disagree & 20 & 15 & 2 & 5 & 22 & 12 \\
\hline Disagree/Strongly Disagree & 26 & 19 & 10 & 24 & 36 & 20 \\
\hline \multicolumn{7}{|c|}{$X^{2}=3.08, d f=2, p=0.21$} \\
\hline \multicolumn{7}{|c|}{ I am happy with the PDR paperwork } \\
\hline Yes & 59 & 44 & 13 & 31 & 72 & 41 \\
\hline No & 76 & 56 & 29 & 69 & 105 & 59 \\
\hline \multicolumn{7}{|c|}{$X^{2}=2.16, d f=1, p=0.14$} \\
\hline \multicolumn{7}{|c|}{ I am clear about what happens to the PDR paperwork } \\
\hline Strongly Agree/Agree & 36 & 27 & 16 & 38 & 52 & 29 \\
\hline Neither Agree nor Disagree & 20 & 15 & 5 & 12 & 25 & 14 \\
\hline Disagree/Strongly Agree & 79 & 59 & 21 & 50 & 100 & 56 \\
\hline
\end{tabular}

Percentage totals may not equal $100 \%$ because of rounding 
The interview data suggested that academics had a range of ambivalent feelings about the principle of the process. For some, the annual meeting was taken as something of a paper exercise; for others it was perceived as a useful opportunity to take stock. But for others it was of vital importance, and there was a strong wish by these individuals to see the Academic Lead treating the PDR meeting even more seriously and using it as a genuine opportunity for open and frank discussion about the nature of the individual's contribution to the Case Study University, about the individual's career goals, and even for creative thinking in relation to approaches to research and/or teaching.

These mixed experiences were also evident from the survey data as shown in table 3, where there were a range of responses to the statement the PDR system is effective on helping me plan, agree action and get support related to my work. However, it can be seen from the table that only 44 academics (33\%) agreed with this statement, while 54 (40\%) did not. Taken with the interview data, these findings suggest that a number of academics value the potential contribution that the process might make to their career and professional development, if it was taken more seriously by managers and seen as an important developmental process by the institution as a whole.

Table 3: Effectiveness and honesty

\begin{tabular}{lcc}
\hline Answer Options (Academics) & n \\
\hline & \\
The PDR system is effective in helping me plan, agree action and get support & 44 \\
related to my work & 33 \\
Strongly Agree/Agree & 37 & 27 \\
Neither Agree nor Disagree & 54 & 40 \\
Disagree/Strongly Disagree & \\
Ifeel that I can be honest about my needs during my meetings & 85 \\
Strongly Agree/Agree & 16 \\
Neither Agree nor Disagree & 33 \\
Disagree/Strongly Disagree & 34 \\
\end{tabular}

Percentage totals may not equal $100 \%$ because of rounding 
From the interviews, positive experiences were related to feeling a sense of purpose in the dialogue afforded by the PDR meetings. For example, Tobias noted that his first PDR conversation 'influenced [his work] quite a bit', in that the AL advised specifically on 'admin duties' and 'realistic timelines for publishing'. For Nick, it's a 'useful tool':

I like the idea of the PDR; I like it... When you look at your CV, it helps to emphasise what you've been doing and also to reflect on what you should do.

Although the data shown in table 3 suggests that a large number of staff do not feel that the PDR process is effective in helping them get support about their work, it appears that the majority of staff surveyed felt they were able to have an open and honest discussion about their needs during their PDR meetings with 85 academics (63\%) agreeing with this statement. However, similarly when compared to the interview data, the respondents had mixed perceptions and experiences with 34 academics (25\%) disagreeing with the statement. These findings relate to the overall purpose of the PDR process and how it is perceived and experienced 'on the ground' and the implications of this will be discussed more fully later in this article.

\section{Paperwork and process}

A number of interview participants noted the change in the format of the paperwork for record keeping under the new system, and they were mostly in favour of the revised 'folder', although the picture here is also somewhat mixed. For example, Jane said:

The PDR form has changed and become more precise. Yes, there are advantages and disadvantages to that, but from my point of view this itemisation of various areas to be targeted is quite good because it focuses my mind on what is required and what I need to do.

Tobias's experience was similar: 
The [PDR form] was very useful for me to sit down and look at the issues... it draws attention to the fact that there are areas I need to work on. But it also draws attention to areas where I feel I have achieved something as well, and I think you need a pat on the back sometimes. You need to feel valued, and that doesn't come through the PDR form, that comes through the conversation with the Lead.

Harold, too, noted the role of the PDR in making academics feel valued:

It's quite nice when somebody recognizes what you've done, because otherwise in academia that never happens.

Ruth described the PDR process as 'good', appreciating the opportunity for discussion

We fill out [the forms] and it makes you think about where you are in your career. I am quite competitive, and I do want to progress, so I think it's a good thing for me, because I can have a checklist of things I want to do.

Katherine has had two Academic Leads because of a change in personnel. One, she felt, managed the PDR poorly because he concentrated on spreadsheets and workload, but her second AL 'has a quiet, calm leadership style' which she appreciated. She was clear that the PDR meeting should not be 'something being done to you, it's your opportunity to take things forward'. She continued:

That gives me ownership. Not 'You will do this, you are in a box, you will perform the following matters; when you've laid your golden egg come and tell me.' It wasn't like that. It was a matter of, 'Here's a way forward, do you want it? Do you not want it? How can I help you? Off you go and let me know how it's going. Great! Independence and ownership.

The format of the PDR was challenged by a number of academics. For a minority, such as Katherine, the hard copy folder provided for the purpose was useful as a collection point for useful 'evidence' of achievement during the year or as a colourful, physical reminder of the activity. Sylvia found the new, more itemized 'folder' more helpful in 
terms of 'mapping of different areas of [her] daily job', which was 'helpful when you need to think seriously about the future'.

However, for most there was a strong sense that everything should be digital and more flexibly conceived. Terry wanted an online system, which is 'live' and genuinely developmental, 'almost like a diary', in which evidence through the year can be both collected and reflected upon:

So then when you start the PDR, you've done the analysis first...That would get really deep.

Others recommend changes to the format of the paperwork to make it more adaptable to different academic 'tracks' - for example, whether the academic is predominantly research-focused or teaching-focused - and others feel it needs to be simpler. For Ruth, for instance, the format, 'needs to be refined. There's too much repetition in the process'; James also referred to there being too much 'overlap' in the process.

These tensions were also evident from the survey data with only 59 academics (44\%) agreeing with the statement, I am happy with the paperwork process associated with the PDR process against $76(56 \%)$ who disagreed. The reasons given by academics for being unhappy with the paperwork are shown in table 4 and include 27 (21\%) who thought that the forms were not helpful, $30(23 \%)$ who thought that they needed to be simplified, $41(32 \%)$ who thought that some of the sections were irrelevant and 30 (23\%) who thought that some of the sections overlapped.

Table 4: Reasons why people are unhappy with PDR paperwork

\begin{tabular}{|c|c|c|c|c|c|c|}
\hline \multirow[t]{2}{*}{ Answer Options (Please tick all that apply) } & \multicolumn{2}{|c|}{ Academics } & \multicolumn{2}{|c|}{$\begin{array}{l}\text { Academic } \\
\text { Leads }\end{array}$} & \multicolumn{2}{|c|}{ Total } \\
\hline & $\mathbf{n}$ & $\%$ & $\mathbf{n}$ & $\%$ & $\mathbf{n}$ & $\%$ \\
\hline Forms not helpful & 27 & 21 & 15 & 29 & 42 & 23 \\
\hline Forms need to be simplified & 30 & 23 & 12 & 24 & 42 & 23 \\
\hline Some sections of the form not relevant to me & 41 & 32 & 13 & 25 & 54 & 30 \\
\hline There are overlaps in sections & 30 & 23 & 11 & 22 & 41 & 23 \\
\hline
\end{tabular}


Percentage totals may not equal $100 \%$ because of rounding

A specific issue arose for some interviewees in relation to those on temporary contracts and whether the format should be different in that case. One participant, Matthew, who was on a temporary contract, had not had a PDR meeting in his year at the Case Study University. He had found other kinds of support in the form of 'junior colleagues just a couple of years ahead' who were 'most helpful in providing advice and guidance about research and teaching' and through the Postgraduate Certificate programme for new staff. In other words, he had had to seek out alternative support networks for his professional development needs.

With very few exceptions, the academics did not know what happened to the PDR form once it had been completed. Some hazarded a guess, but most felt that they probably got simply filed away and no one looked at them other than the academic and AL. Amy's comment was typical:

I don't even know if [the PDR records] ever get looked at...I know my AL signs them, and then I send them off to - I can't even remember who it is, and I don't know where they go. I don't know if anything comes from it. If there's no buy in from the people above it does seem a bit pointless that these forms are just getting lost in the ether.

As can be seen from table 2, these frustrations were also reflected in the survey data with 79 academics (59\%) disagreeing with the statement I am clear about what happens to the PDR paperwork compared with only $36(27 \%)$ who agreed with the statement. From the interview data, there was a consistent request that this process be made more explicit, and that the PDR system be used as a means of highlighting good practice and managing a complex institution by recognizing more effectively the potential 
contributions of individual academics to the organization as a whole. These messages were confirmed through the survey data.

The success of the Professional Development Review process overall appears to be contingent upon the extent to which the principles of 'good' leadership are operating, rather than on specific configurations of paperwork or timings of reviews. Indeed, only 21 out of 135 academics (16\%) disagreed with the statement I think the timing of the PDR meetings is about right (as can be seen in table 2). Consistently, however, through both the interview and survey data, there was a perceived lack of clarity in relation to what happens to the PDR paperwork once it has been completed, and its role in furthering the needs of either the institution or the individual. This appears to be a key issue that Case Study University needs to address and will be discussed more fully later.

\section{How do Academic Leads perceive and experience the PDR process?}

\section{Overall purpose}

Our findings suggest that there is a general understanding among the Academic Leads interviewed of the purpose of the review process and the values which underpin it. These results are also reflected in the survey data with 30 ALs (71\%) agreeing that they are clear about the purpose of the PDR (as shown in table 2). However, with 10 ALs (24\%) disagreeing with the statement, there is clearly some work to be done by the Case Study University in ensuring that all ALs are clear on the purpose and role of the PDR, especially as they will be the ones leading the process within their departments. In fact, a Chi-square test showed that there was no statistically significant association between job role and clarity of purpose in our findings $\left(\mathrm{X}^{2}=3.08, \mathrm{df}=2, \mathrm{p}=0.21\right)$ with a total of 58 staff (32\%) either disagreeing or giving a neutral response to this question. 


\section{Training}

One way of ensuring the aims of the PDR are clear for ALs may be to look at the training and support activities which are in place linked to the process. Table 5 shows that when Academic Leads were asked whether they had had sufficient training about the process, 21 ALs (50\%) disagreed. The discrepancy in these results, between ALs who feel that they need more training and those that don't, suggest that any training linked to the PDR process should be individually tailored to ensure that ALs who feel they need it can take it up, without assuming that all staff in the role of AL need the same levels of training and support.

Table 5: Training

\begin{tabular}{lll}
\hline I have had sufficient training about the PDR process (Academic Leads) & n & $\%$ \\
\hline & & \\
Strongly Agree/Agree & 16 & 38 \\
Neither Agree nor Disagree & 5 & 12 \\
Disagree/Strongly Disagree & 21 & 50
\end{tabular}

Percentage totals may not equal $100 \%$ because of rounding

Underlying principles

As with the academics participating in the study, from the interviews the principle of a regular review as part of an academic's professional and career development was very broadly supported. As an example, Arthur described the PDR meeting as an opportunity for:

being reflective with one's own practice and making professional judgments, and that's what I try to encourage the people I lead to do.

For Arthur, the details of the academic's performance, for instance in student evaluations, was not as important as the opportunity to have 'an open discussion about how to improve', and 'trying to understand how to do that in the future better, rather 
than hammering someone for not performing according to some metric.' Francis, too, saw the value in the PDR process:

There are two things that are valuable: one is that particularly junior people at least have the name of somebody that they know that would in theory be an appropriate person [to approach] should they have some kind of real professional concern... And the second is that there is at least an annual meeting to review progress, look at what they've been trying to achieve and how that might have changes, and so on...

A number of ALs interviewed, as with the data from the academics, raised the issue of a potential gap between the intentions, interests and values of the academic reviewed and the expectations or requirements of the university. Francis perceived, however, that the PDR is an opportunity for these dual interests to coincide:

There's no reason, certainly in the modern age, why the goals of the individual academic cannot align with the goals of the institution... But talking to somebody about their personal career goals will include things like not being fired by the university, being promoted - so obviously they do come together in a certain way and the structure of the [PDR] form we work through makes sure that happens.

\section{Paperwork and process}

There was a mixed response to the Case Study University's new PDR folders, which are more detailed than the previous PDR forms, showing a range of topics to be discussed at the Review. Arthur saw them as useful as a 'scrapbook to record the various things they are doing', but for George, the PDR forms needed to be in digital form, so reviewees can let them grow and change, rather than in hard copy form. For Chris, the paperwork reflected a move towards a more performative process than one that would be more beneficial for staff: 
Obviously, we have a set of goals implied here, but it's very disparate as it is in all academia, so you can't have it as a tick box exercise. But we have moved slightly towards that with the new paperwork...We need to look at ways of linking the PDR annually with performance for career building... and need to make it clear as well where it can aid promotion and act as a guide.

Along with several other interviewees, Chris also wanted more clarity about the criteria 'against which they're measuring themselves, so that they can advance,' and wanted to have relevant performance data available, such as student evaluations. However, there remained concern for a number of academics about whether some of the criteria and targets were applied too zealously to diverse individuals in a way which was insufficiently nuanced. Some, like Evelyn, commented particularly upon the demanding targets for achievement expected by early career academics still on probation and wanted these reviewed.

For Lisa, the PDR was a good idea in that a formalized review process was needed, but she felt that the current PDR forms were not particularly helpful for academic staff who are on teaching-focused contracts; it was 'too rigid', as some of the elements are not applicable. George, in a similar vein, felt that the forms don't quite work for academics on the education and scholarship track: 'A little more thought could have then gone into what it means to be an academic lead of education and scholarship staff.' Others expressed a desire for differentiated forms to suit staff on different types of academic contract, or at different stages in their career. For example, Ian found it inappropriate to be asking brand new staff about their contribution to 'internationalization', which is one of the PDR themes. Nel also noted the difficulty of working through a personal development plan for staff on very fractional contracts.

These issues with the paperwork were reflected strongly in the survey data, as shown in table 2 . Here it can be seen that 29 ALs (69\%) disagreed with the statement $I$ 
am happy with the paperwork associated with the PDR process against only 13 ALs

(31\%) who agreed. In addition, a Chi-square test showed that there was no statistically significant association between job role and perceived happiness with the paperwork, $\mathrm{X}^{2}=2.16, \mathrm{df}=1, \mathrm{p}=0.14$ (see table 2 ). The reasons given for why academic leads were unhappy with the paperwork are shown in table 4 and include 15 ALs (29\%) who felt that the forms were not helpful, 12 (24\%) who thought the forms needed to be simplified, $13(25 \%)$ who thought that some sections of the form were not relevant and $11(22 \%)$ who felt that there were overlaps in the sections of the forms. These findings, combined with similar data from the academics presented in the previous section, point to the fact that the Case Study University may need to review the forms it uses for the purpose of PDR and reflect on the importance of these forms in reflecting the purposes of the process as a whole. This issue will be more fully discussed in the next section.

Some Academic Leads who were interviewed saw a wasted opportunity in not making more of the outcomes of the PDR meetings and records, by using them more systematically to inform activities. Nel felt that the PDR paperwork 'seems to disappear into a kind of black hole... It seems that the process ends with me'. Brandon referred to the challenge of getting relevant information from the PDRs back into faculty-level decision making; there needs to be a 'summary of issues ... that need to be highlighted to the college ... so that we as a faculty can understand where problems are arising'. Martin agreed:

It's not clear to me that the often very important and significant problems that people experience, which are not so much personal as systemic, get collated and fed back and dealt with.

He explained at some length his views on what could be done more effectively: 
It's part of a good conversation, actually. It gives [colleagues] chance to blow off steam [although] it's not always stuff I can do anything about. It would be helpful if there was some onward person or centralized depot where generic complaints could go, because I mean apart from letting off steam it is not clear to me where this stuff is collected, where it goes and feeds into ... policy making or into administrative routines. It's asymmetrical ... in the sense that it's focused much more on what the person is doing rather than reflecting the experience of personnel to an administrative apparatus which often fails to deliver... It is not clear that the problems or difficulties that the personnel are experiencing get focused to a place where something might be [dealt with] systematically... And it's not clear that I have any power to respond, you know, or change the environment of the person for whom I am the Academic Lead.

These experiences were also reflected as the majority view from the survey data, with 21 ALs (50\%) disagreeing with the statement I am clear what happens with the PDR paperwork compared to 16 (38\%) who agreed. This number seems especially high when we consider that the ALs are the people who are meant to be leading the PDR process within the Case Study University's management structure. Indeed, a further Chi-square test showed that there was no statistically significant association between job role and perceived clarity about what happens to the paperwork, $X^{2}=2.03, \mathrm{df}=2, \mathrm{p}$ $=0.36$.

In summary, the perspectives of the Academic Leads on the PDR process are on the whole congruent with those of the academics with no statistically significant associations being found between job roles and measures related to clarity of purpose and paperwork processes. Our results from both data sets show that the conversation is perceived to be potentially very important and could offer significant levels of guidance and support for staff. However, the Academic Leads stressed the importance of a review structure which was more adaptable, and with clearer guidance on how to make sense of relevant data (such as research income gained and student evaluation scores). They also 
emphasized the need to make more of the outcomes of the PDRs in terms of feeding into wider decision-making processes.

\section{Discussion}

Although a formal PDR process was acknowledged by the majority of academics and managers as having the potential to provide a necessary and helpful framework for an individual's professional development, this study found that the real purpose of the PDR process at the case study university was ambiguous with almost a third (32\%) of all staff surveyed being unclear about its purpose and no statistically significant differences being found between leaders and the staff they lead in this regard. Key variations here formed around whether as it was conceived for individual professional development or for compliance and control. In the official PDR documentation, the process was claimed to enable the reconciliation of individual staff development needs with the overall strategic goals of the University. However, it was clear that this espoused theory was either misunderstood or seen as unworkable or unachievable as a theory in use (Argyris et al. 1985; Argyris and Schon 1974) by a sizeable number of staff. This was due to some staff and a number of managers viewing the process more as an aspect of performativity (Ball 2003; 2012) than a positive model of professional development and consequently mistrusting these espoused messages. These findings also suggest a worrying mismatch and communication breakdown between senior leaders (those who had devised the scheme and written the policy frameworks) and those middle leaders who needed to implement the process on the ground. This communication breakdown was also apparent from academics' perceptions of the process and points to the fact that developing and clearly communicating the vision and purpose of the scheme is crucial and that more work is required at the Case Study University so that all participants and 
leaders come to a shared understanding of the aim of the exercise.

One way of overcoming this problem may be to develop more learning opportunities for staff with many leaders highlighting the fact that they needed more training to help them undertake PDRs. However, the findings also suggested that, as has been found in other studies exploring academic leader's development needs, individualised training in this area would appear to be much more beneficial for staff rather than blanket "all must attend" courses. This is due to the fact that individuals all have different levels of knowledge and experience in such areas and it cannot be assumed that one size fits all in relation to higher education leadership development training (Floyd 2016; Gerken et al. 2016; Preston and Floyd 2016).

A large number of staff felt that the PDR process was ineffective in helping support their work, with $25 \%$ feeling that they could not be honest about their needs during the meetings. Several staff also wanted more clarity about the criteria being used as benchmarks and the overzealous target setting culture evident, especially for early career academics; furthermore, there appeared to be a gap in support for those on temporary contracts. In addition, most academics and leaders were unhappy with the paperwork process associated with the PDR process with no statistically significant differences being found between the two groups. All these findings suggest that the PDR process in the Case Study University has perhaps been characterised by language, procedures and bureaucracy perceived to be part of a neo-liberal culture of performativity rather than as an integral aspect of a professional's goal to continually develop in their role, which in turn would help motivate and inspire staff and allow the institution to move towards its strategic goals by default. By reducing the PDR process to a literal tick box exercise, some staff perceived it as being antithetical to the values that brought them into the profession in the first place, with the rigidness of the form 
seemingly taking away the ability to be flexible and autonomous in reflecting on their individual professional development needs. These findings suggest that any paperwork or similar online forms devised to help support such schemes need to be very carefully thought through and should be designed by talking to staff at all levels and roles, including those on temporary contracts, to ensure that all opinions and voices are heard. These actions may well also increase the sense of ownership that staff would feel about the process and therefore contribute to a more positive perception of PDRs in general.

Finally, the majority of academic staff and leaders at the Case Study University did not seem to know what happened to the PDR paperwork once it has been completed and, once again, there was no statistically significant difference found between the two groups here in relation to this point. This lack of clarity demoralises staff and managers and reduces their sense of value and worth as it appears that the process is not being taken seriously by senior leaders in the organisation. In addition, important information and data which could feed back into faculty wide and university wide processes, and thus contribute to the successful attainment of institutional goals, were being overlooked and ignored.

\section{Conclusions}

In conclusion, the findings from this study suggest that leaders and the staff they lead felt that the PDR process (especially one to one conversations) was potentially very important and could offer significant levels of guidance and support for professional development. However, they stressed the importance of a review structure which was adaptable, individualised, more professionally relevant, and less reliant on over ambitious target setting. They also emphasized a need to make more of the outcomes of the PDRs in terms of feeding into wider decision-making processes and the future 
individual CPD needs of those involved. In this way, the process can be conceived as an important developmental process which can be valued by both academics and leaders, contributing both to professional development but also as a means of ensuring institutions have the necessary information and staff motivation to successfully compete in an increasingly accountable, fast changing and competitive market place (Bendermacher 2017). Thus, the PDR process can be seen as a crucial aspect of staff development positively influencing research, teaching and learning and student outcomes (De Rijdt et al. 2013; Saroyan and Trigwell 2015; Williams et al. 2016) as opposed to a performative process based on notions of surveillance and a perceived lack of trust (Ball 2003; 2012) which can be perceived as threatening traditional academic values (Lambrechts et al. 2017) and possibly having a negative effect on staff morale and performance (Teh et al. 2012). Viewed as such, the PDR can be both positively espoused and enacted by senior leaders, managers and academics throughout the organisation (Argyris et al. 1985; Argyris and Schon 1974).

As highlighted in the introduction, very little is known about how staff in different job roles perceive and experience the PDR process in the higher education sector. By comparing data from both managers and academics and using an analytical framework based on the concepts of professional development and performativity, it is argued that this article provides a significant and original contribution to our knowledge in this area. While not claiming to be generalisable, it is hoped that these findings are helpful for academics, appraisers and senior leaders in developing PDR processes that are fit for purpose and that help reconcile the professional development needs of the individual staff member with the wider goals of the institution. More research is clearly required to help develop our understanding of the PDR process, focused on different institutional types and larger data sets both nationally and internationally. However, it is 
crucial that any such research continues to include the perspectives and experiences of academics as well as those in leadership positions in order to provide a balanced view of staff experiences in this area.

\section{Acknowledgements}

The research on which this article is based was funded by the Leadership Foundation for Higher Education and undertaken with Professor Dilly Fung. I gratefully acknowledge their support. Interpretations and errors remain my own.

\section{References}

Argyris, C., R. Putnam and D. Mclain Smith. 1985. Action science: Concepts, methods, and skills for research and intervention. San Francisco: Jossey-Bass.

Argyris, C. and D. Schon. 1974. Theory in practice: Increasing professional effectiveness. San Francisco: Jossey-Bass.

Arthur, L. 2009. From performativity to professionalism: Lecturers' responses to student feedback. Teaching in Higher Education 14, no 4: 441-54.

Ball, S.J. 2003. The teacher's soul and the terrors of performativity. Journal of Education Policy 18, no 2: 215-28.

Ball, S.J. 2012. Performativity, commodification and commitment: An i-spy guide to the neoliberal university. British Journal of Educational Studies 60, no 1: 17-28.

Bendermacher, G.W.G. 2017. Unravelling quality culture in higher education: A realist review. Higher education 73, no 1: 39;60;-60.

Bera. 2011. Ethical guidelines for educational research. London: British Educational Research Association.

Bremner, S. 2011. Academic institutions as corporate enterprise: Transparency, power and control in staff appraisal. International Journal for the Semiotics of Law Revue internationale de Sémiotique juridique 24, no 2: 147-61.

Bubb, S. and P. Earley. 2007. Leading and managing continuing professional development. Second ed. London: Paul Chapman Publishing.

Creswell, J. 2014. Research design. fourth ed. London: Sage.

De Rijdt, C., A. Stes, C. Van Der Vleuten and F. Dochy. 2013. Influencing variables and moderators of transfer of learning to the workplace within the area of staff 
development in higher education: Research review. Educational Research Review 8: 48-74.

Deem, R., S. Hillyard and M. Reed. 2007. Knowledge, higher education, and the new managerialism : The changing management of uk universities. Oxford: Oxford University Press.

Evans, L., M. Homer and S. Rayner. 2013. Professors as academic leaders: The perspectives of 'the led'. Educational Management Administration \& Leadership 41, no 5: 674-89.

Floyd, A. 2016. Supporting academic middle managers in higher education: Do we care? Higher Education Policy 29, no 2: 167-83.

Floyd, A. and D. Fung. 2017. Focusing the kaleidoscope: Exploring distributed leadership in an english university. Studies in Higher Education 42, no 8: 1488503.

Floyd, A. and D. Fung. 2018. Stories of leading and being led: Developing collaborative relationships in an english research-intensive university. In Exploring consenual leadership in higher education, ed. Gornall, L, Thomas, B. And Sweetman, L. London: Bloomsbury Academic.

Gast, I., K. Schildkamp and J.T. Van Der Veen. 2017. Team-based professional development interventions in higher education: A systematic review. Review of Educational Research 87, no 4: 736-67.

Gehlbach, H. and M.E. Brinkworth. 2011. Measure twice, cut down error: A process for enhancing the validity of survey scales. Review of General Psychology 15, no 4: 380-87.

Gerken, M., S. Beausaert and M. Segers. 2016. Working on professional development of faculty staff in higher education: Investigating the relationship between social informal learning activities and employability. Human Resource Development International 19, no 2: 135-51.

Hitch, D., P. Mahoney and S. Macfarlane. 2018. Professional development for sessional staff in higher education: A review of current evidence. Higher Education Research \& Development 37, no 2: 285-300.

Lambrechts, W., E. Verhulst and S. Rymenams. 2017. Professional development of sustainability competences in higher education. International Journal of Sustainability in Higher Education 18: 697-714. 
Lichtman, M. 2013. Qualitative research in education: A user's guide. Third ed. Thousand Oaks, California: Sage.

Makunye, M.M. and T.G. Pelser. 2012. Academic staff's apathy towards formal professional development programmes at north-west university. South African Journal of Higher Education 26, no 3: 529-45.

Morse, J.M. and L. Niehaus. 2009. Mixed methods design: Principles and procedures. Abingdon, Oxon, UK: Routledge.

Mulà, I., D. Tilbury, A. Ryan, M. Mader, J. Dlouhá, C. Mader, J. Benayas, J. Dlouhý and D. Alba. 2017. Catalysing change in higher education for sustainable development: A review of professional development initiatives for university educators. International Journal of Sustainability in Higher Education 18, no 5: 798-820.

Nardi, P. 2018. Doing survey research. Fourth ed. New York: Routledge.

Preston, D. and A. Floyd. 2016. Supporting the role of associate dean in universities: An alternative approach to management development. Higher Education Quarterly 70, no 3: 264-80.

Saroyan, A. and K. Trigwell. 2015. Higher education teachers' professional learning: Process and outcome. Studies in Educational Evaluation 46: 92-101.

Teh, C.J., A. Boerhannoeddin and A. Ismail. 2012. Organizational culture and performance appraisal process: Effect on organizational citizenship behavior. Asian Business and Management 11, no 4: 471-84.

Williams, L., S. Nixon, C. Hennessy, E. Mahon and G. Adams. 2016. Inspiring to inspire: Developing teaching in higher education. Cogent Education 3, no 1. 